\title{
InP/ZnS as a safer alternative to CdSe/ZnS core/shell quantum dots: in vitro and in vivo toxicity assessment
}

\author{
Virgilio Brunetti, ${ }^{a}$ Hicham Chibli, ${ }^{b}$ Roberto Fiammengo, ${ }^{a}$ Antonio Galeone, ${ }^{a}$ \\ Maria Ada Malvindi, ${ }^{a}$ Giuseppe Vecchio, ${ }^{a}$ Roberto Cingolani, ${ }^{c}$ Jay L. Nadeau ${ }^{b}$ \\ and Pier Paolo Pompa*a
}

\begin{abstract}
We show that water soluble InP/ZnS core/shell QDs are a safer alternative to CdSe/ZnS QDs for biological applications, by comparing their toxicity in vitro (cell culture) and in vivo (animal model Drosophila). By choosing QDs with comparable physical and chemical properties, we find that cellular uptake and localization are practically identical for these two nanomaterials. Toxicity of CdSe/ZnS QDs appears to be related to the release of poisonous $\mathrm{Cd}^{2+}$ ions and indeed we show that there is leaching of $\mathrm{Cd}^{2+}$ ions from the particle core despite the two-layer ZnS shell. Since an almost identical amount of In(III) ions is observed to leach from the core of InP/ZnS QDs, their very low toxicity as revealed in this study hints at a much lower intrinsic toxicity of indium compared to cadmium.
\end{abstract}

Received 3rd October 2012 Accepted 26th October 2012

DOI: $10.1039 / \mathrm{c} 2 \mathrm{nr} 33024 \mathrm{e}$

www.rsc.org/nanoscale

\section{Introduction}

Quantum dots (QDs), fluorescent semiconductor nanocrystals, are a very interesting class of nanomaterials with important imaging applications in biology and medicine. ${ }^{1}$ However, it was realized early in their development that the use of these materials poses serious concerns about toxicity and safety, especially because the most popular and well-studied QDs contain cadmium: CdSe, CdTe, and CdS. Cd is known to be highly toxic and carcinogenic for living systems. Several investigations of Cd-based QDs have quantified the toxicity of these materials in cell cultures and suggested strategies to reduce it. ${ }^{2}$ Most QDS used for biological applications are not bare core particles, but possess shell layers of other materials in order to improve optical properties and prevent QD breakdown in solution. A "shell" of one to two monolayers of $\mathrm{ZnS}$ is needed to improve the quantum yield of CdSe QDs to values useful for imaging. In addition to that shell, the QDs can be rendered water-soluble by highly stable silica shells or polymers. ${ }^{3}$ While a shell plus a stable organic coat significantly reduce $\mathrm{Cd}^{2+}$ leaching, it still remains questionable whether QDs could ever be approved for medical applications. A promising alternative is the use of QDs based upon Cd-free materials, such as InP. As with CdSe, InP cores must be protected by a ZnS shell to prevent core breakdown. Only a few studies on the toxicity of InP QDs have been

astituto Italiano di Tecnologia (IIT), Center for Bio-Molecular Nanotechnologies@ UniLe, Via Barsanti, 73010 Arnesano, Lecce, Italy. E-mail: pierpaolo.pompa@iit.it; Fax: +39-0832-295708; Tel: +39-0832-295714

${ }^{b}$ Department of Biomedical Engineering, McGill University, 3775 Rue University, Montreal, QC H3A 2B4, Canada

${ }^{c}$ Istituto Italiano di Tecnologia (IIT), Central Research Laboratories, Via Morego, 30, 16136 Genova, Italy published and most of them have been of limited breadth, focusing mostly on toxicity in cell culture. Even if InP-based QDs appear to be a safer alternative to Cd-containing QDs, there is still very little known about their toxicity in vivo, and there is so far no example for a direct comparison with Cd-containing QDs. ${ }^{4}$

This work presents in vitro (cell culture) as well as in vivo (animal model) toxicity assessment of water-soluble InP/ZnS and CdSe/ZnS QDs. It provides a direct comparison of the impact of the QD core material on toxicity in cells and in animals. The only difference between the two investigated types of QDs is the chemical nature of their core (InP $v s$. CdSe) while all other properties known to affect cellular responses - particle size, charge, shell and surface chemistry - are kept constant. Under these identical conditions, it is confirmed that InP QDs show greatly reduced toxicity compared to CdSe QDs, making them a valuable alternative for biologically oriented applications.

\section{Results and discussion}

\section{QD preparation and characterization}

Water-soluble InP/Zns and CdSe/ZnS QDs (both with two ZnS shell layers) capped with mercaptopropionic $\operatorname{acid}^{5}$ were prepared according to published procedures..$^{5-7}$ The materials were investigated via TEM (Fig. 1A and B) and found to be monodisperse and with a narrow size distribution. Comparable dimensions $(11.3 \pm 0.6 \mathrm{~nm}$ for $\mathrm{InP} / \mathrm{ZnS}$ and $13.4 \pm 0.7 \mathrm{~nm}$ for $\mathrm{CdSe} / \mathrm{ZnS}$ ) and narrow size distributions were confirmed by dynamic light scattering (DLS, Fig. 1E and F). The surface charge was similar for both types of nanocrystals $(-26 \pm 9 \mathrm{mV}$ for InP/ZnS and $-24 \pm 5 \mathrm{mV}$ for CdSe/ZnS, Fig. 1C and D). An 

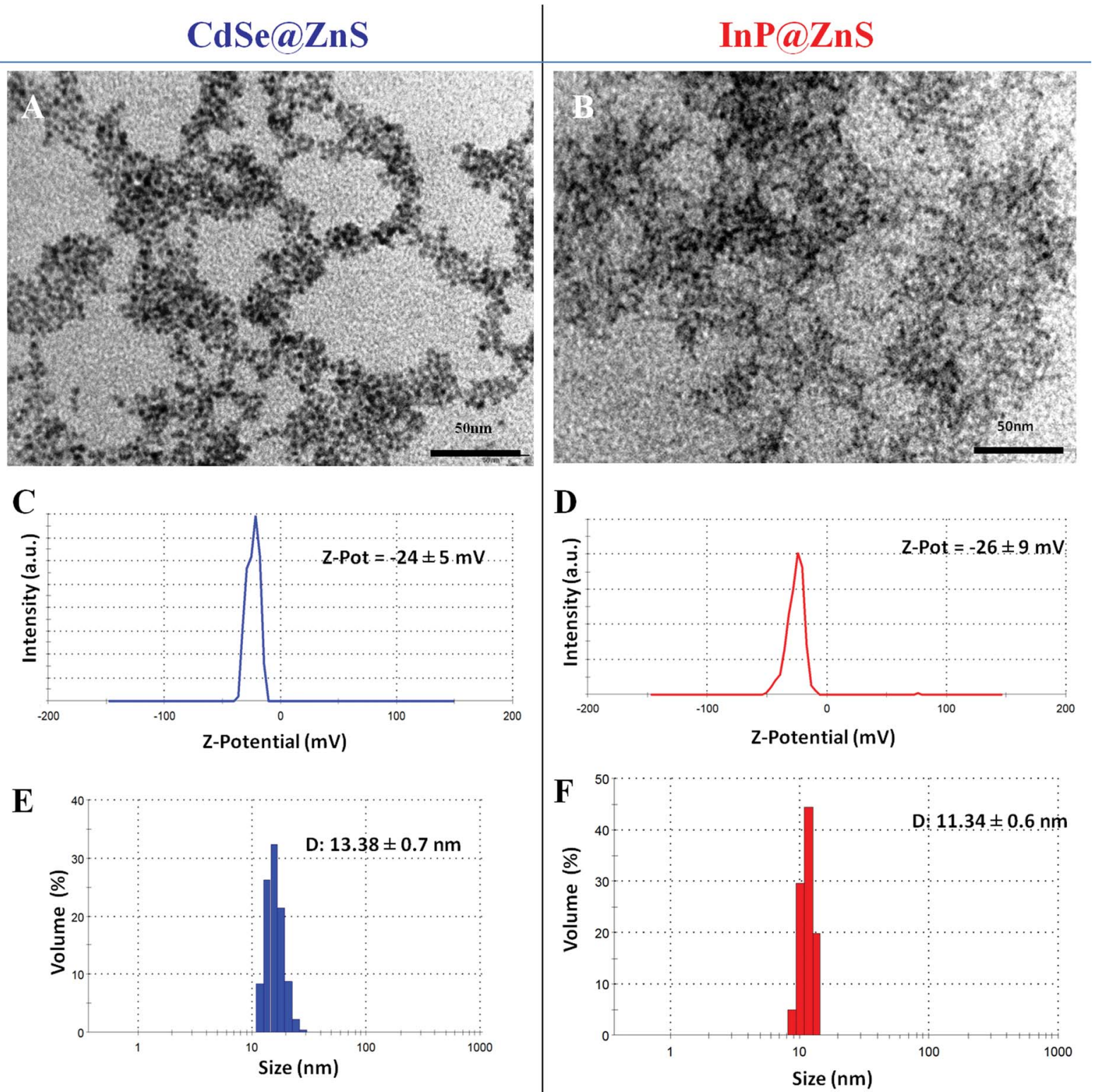

G

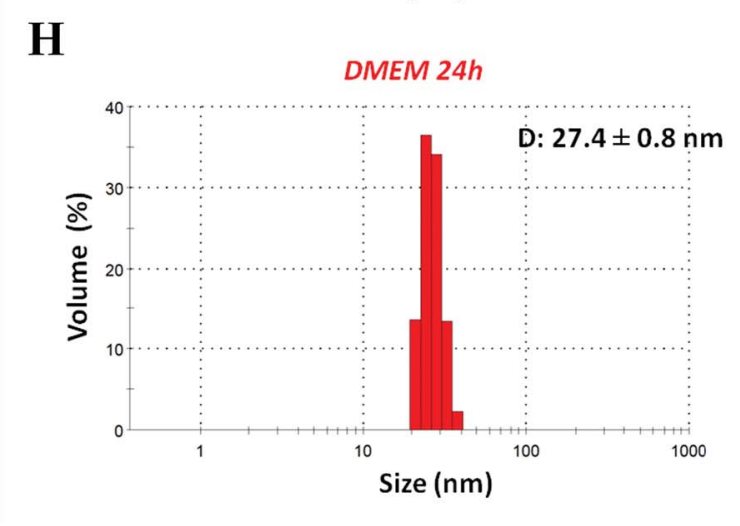

Fig. 1 (A and B) TEM images of water-dispersible CdSe/ZnS and InP/ZnS QDs; (C and D) $\zeta$-potential analyses and (E and F) DLS plots of CdSe/ZnS and InP/ZnS QDs dispersed in water and ( $\mathrm{G}$ and $\mathrm{H}$ ) after $24 \mathrm{~h}$ incubation in DMEM supplemented with $10 \% \mathrm{FBS}$ at $37^{\circ} \mathrm{C}$. DLS values are the average of at least 10 runs of 15 measurements. $\zeta$-potential values are the average of at least 10 runs of 30 measurements. 


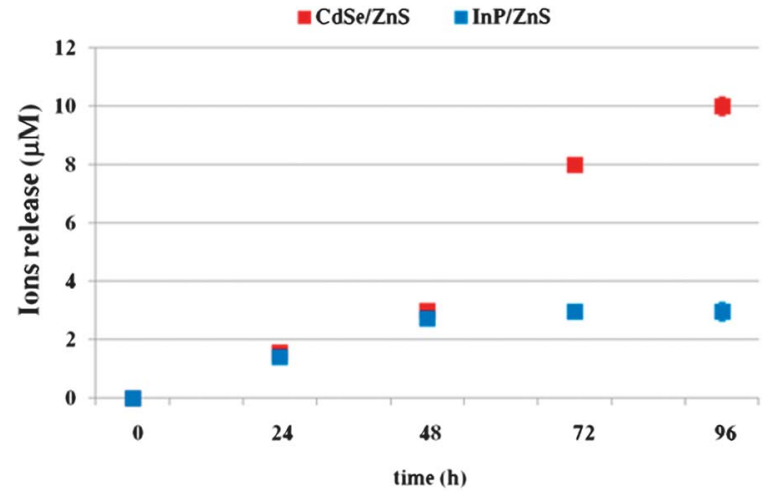

Fig. 2 Time-dependent release of cadmium or indium ions from CdSe/ZnS and InP/ ZnS QDs, respectively, in an aqueous environment mimicking lysosomal conditions $\left(37^{\circ} \mathrm{C}, \mathrm{pH} 4.5\right)$. Data are reported as mean \pm SD. All values were consistent among triplicates performed in the same experiment, with error bars smaller than symbols.

increase in the QD dimensions to approx. $30 \mathrm{~nm}$ (Fig. 1G and $\mathrm{H}$ ) was observed in both cases after $24 \mathrm{~h}$ incubation in cell culture medium (DMEM supplemented with 10\% fetal bovine serum,
FBS), which reflects the formation of a protein corona around the QDs, as already observed for other kinds of nanoparticles. ${ }^{8-10}$

The release of metal ions from the QD core was quantified over a period of $96 \mathrm{~h}$ under simulated lysosomal conditions $\left(37^{\circ} \mathrm{C}\right.$, citrate buffer $\left.\mathrm{pH} 4.5\right)$. Incubation of $40 \mathrm{nM}$ QDs for $48 \mathrm{~h}$, which correspond to $854 \mu \mathrm{M} \mathrm{Cd}$ and $835 \mu \mathrm{M}$ In, led to leaching of approximately $3 \mu \mathrm{M}$ core metal ions for both nanocrystal types (Fig. 2). For longer times, we observed a higher release of cadmium compared to indium, indicating a higher stability of InP/ZnS QDs towards hydrolysis, probably due to the robustness of the covalent bond in III-V semiconductors. ${ }^{11}$

\section{In vitro toxicity investigations}

A first set of experiments compared the toxicity of water soluble InP/ZnS and CdSe/ZnS QDs in vitro. The epithelial cell line A549 (human lung carcinoma) and the neuronal cell line SH SY5Y (human neuroblastoma) were chosen for these investigations and cultivated in the presence of increasing concentrations of CdSe/ZnS or InP/ZnS QDs (1 pM to $5 \mathrm{nM}$ ). Cell viability was
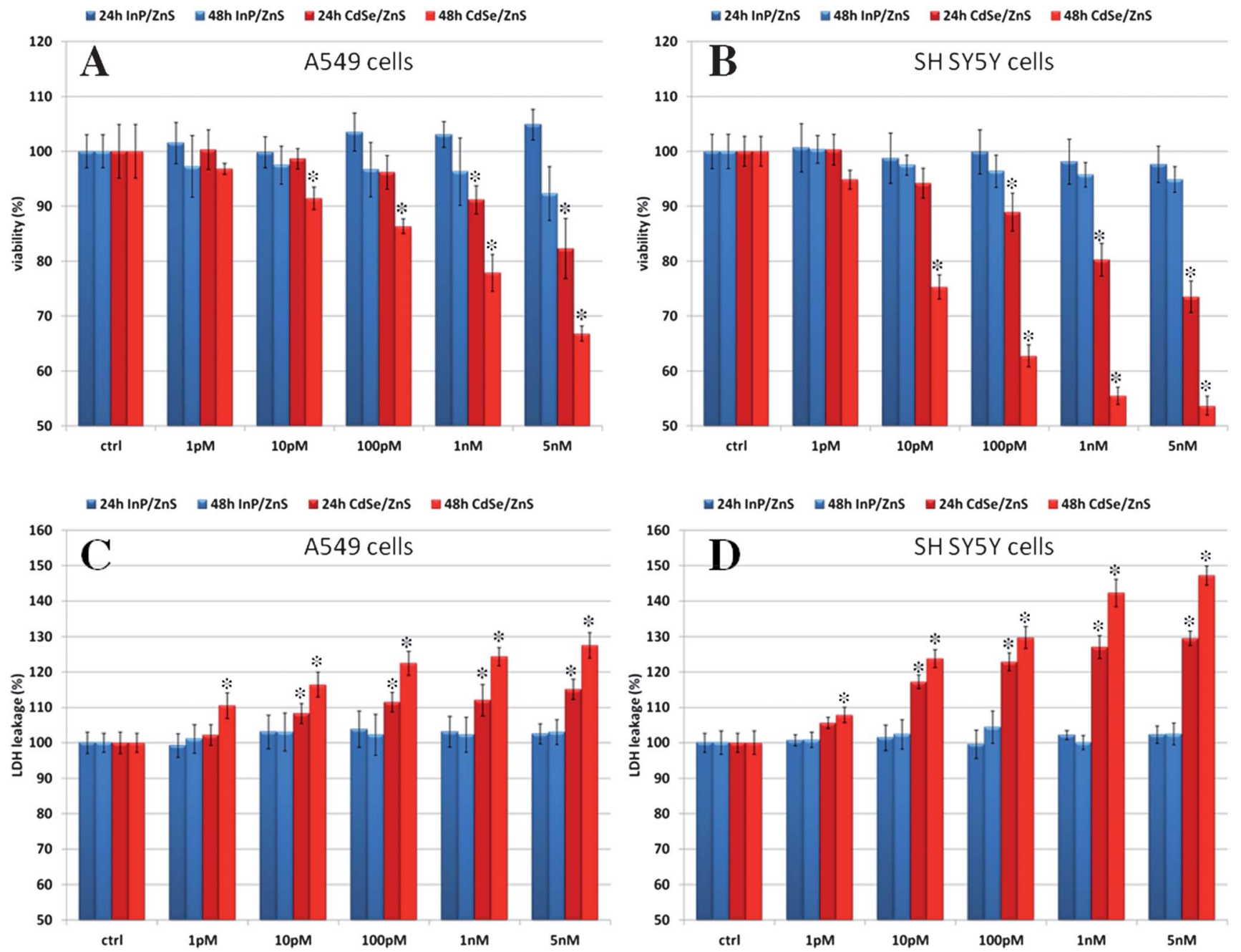

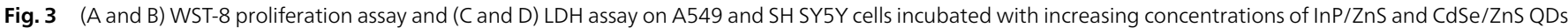

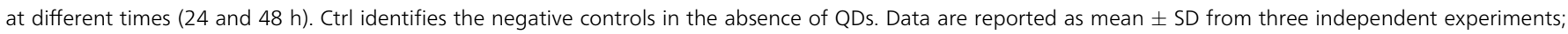
${ }^{*} P<0.05$ compared with control $(n=8)$. 
measured after 24 and $48 \mathrm{~h}$ incubation using the WST-8 test (Water-Soluble Tetrazolium salt). As expected, CdSe/ZnS QDS produced a significantly larger decrease in cell viability compared to InP/ZnS QDs. ${ }^{5}$ The toxic effect of Cd-containing QDs was clearly observable after $24 \mathrm{~h}$ incubation at $1 \mathrm{nM}$ concentration (Fig. 3A and B). In the case of prolonged exposure (48 h), a detectable reduction in cell viability was observed for $\mathrm{CdSe} / \mathrm{ZnS}$ QD concentrations as low as $10 \mathrm{pM}$. The highest toxicity was found for the neuronal cell line, with a $27 \%$ viability loss after $24 \mathrm{~h}$ which grew up to $46 \%$ after $48 \mathrm{~h}$ (Fig. 3B, red bars) with $5 \mathrm{nM}$ CdSe/ZnS QDs. The epithelial cell line appeared to be more resistant under these conditions, with a loss of viability of $33 \%$ after $48 \mathrm{~h}$ (Fig. 3A, red bars) with $5 \mathrm{nM}$ CdSe/ZnS. In contrast, incubation for $48 \mathrm{~h}$ with $5 \mathrm{nM} \mathrm{InP} / \mathrm{ZnS}$ QDs produced only a statistically insignificant reduction in cell viability $(<10 \%)$ for both cell lines (Fig. 3A and B, blue bars).

To better understand the molecular reasons underlying the observed reduction in cell viability, we performed a series of additional assays. The LDH (lactate dehydrogenase) leakage assay was used to gain information about possible cell membrane damage. The results showed that indeed the treatment with CdSe/ZnS QDs induced significant membrane damage in both cell types, possibly at concentrations as low as $1 \mathrm{pM}$, already observable after $24 \mathrm{~h}$ for the neuronal cell line and after $48 \mathrm{~h}$ for the epithelial line (Fig. 3C and D, red bars). By comparison, no significant increase in LDH was observed upon incubation with $\mathrm{InP} / \mathrm{ZnS}$ QDs at any time and tested concentration compared to the controls (Fig. 3C and D, blue bars).

QD-treated cell cultures were also investigated to detect the occurrence of oxidative stress. A positive DCF-DA (dichloro fluorescein diacetate) assay after incubation of cell cultures with as little as $1 \mathrm{pM}$ Cd-containing QDs for $24 \mathrm{~h}$ (data not shown) indicated generation of intracellular reactive oxygen species (ROS). However, it has been reported that quantification of ROS generated by Cd-containing QDs via this assay may lead to overestimation of ROS levels, possibly due to direct interaction of photooxidized QDs with the dye. ${ }^{12}$ To confirm the induction of ROS caused by oxidative stress, we used here additionally real-time qPCR and followed the expression levels of SOD1, SOD2, CAT, and Gpx genes coding for antioxidant and detoxifying enzymes. The induction of antioxidant enzymes, such as superoxide dismutase (SOD), catalase (CAT), and glutathione peroxidase (Gpx), is observed upon treatment with low concentrations of a wide variety of chemical agents as well as a consequence of physical stress. Together with high intracellular levels of glutathione (GSH), these enzymes protect the cell from oxidative stress, which may cause lethal damage to DNA, RNA, proteins, and lipids. SOD quenches the free radical superoxide by converting it to peroxide, which can then be inactivated by reactions catalyzed by CAT or Gpx. CAT disproportionates intracellular hydrogen peroxide to water and molecular oxygen and Gpx, a selenium-containing peroxidase, catalyzes the
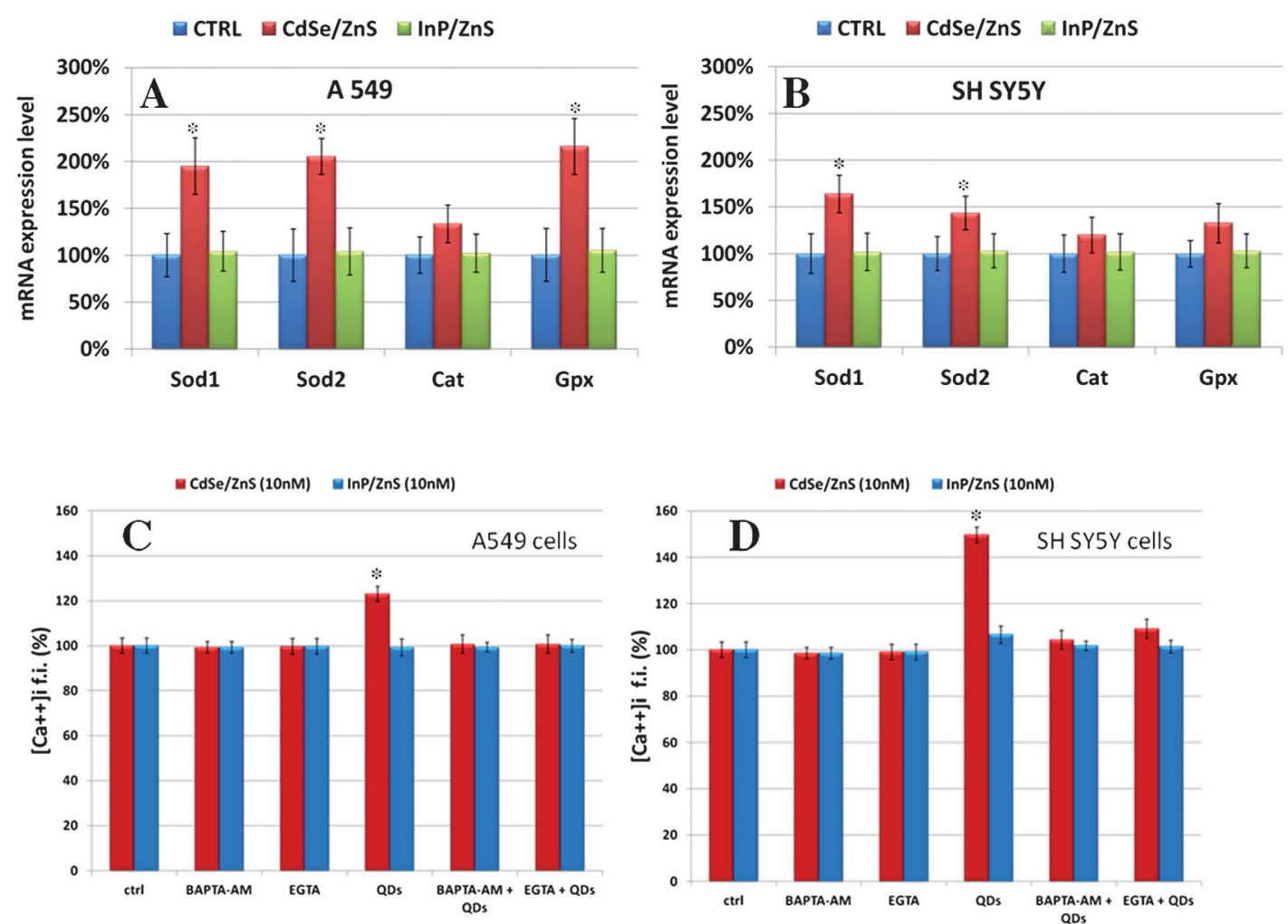

Fig. 4 mRNA expression level analyzed by RT-qPCR of A549 (A) and SH SY5Y (B) cells treated with $5 \mathrm{nM}$ CdSe/ZnS or InP/ZnS QDs for 24 h. Data are reported as mean \pm SD from three independent experiments; ${ }^{*} P<0.05$ compared with control $(n=8)$. [ $\left[\mathrm{Ca}^{2+}\right]_{\mathrm{i}}$ measurements for A549 (C) and SH SY5Y (D) cells treated with $10 \mathrm{nM}$ InPI $\mathrm{ZnS}$ or CdSe/ZnS QDs for $24 \mathrm{~h}$. Cells were pretreated with BAPTA/AM or EGTA in the presence or in the absence of QDs. Data are reported as mean \pm SD from three independent experiments; ${ }^{*} P<0.05$ compared with control $(n=8)$. 
reduction of a variety of hydroperoxides using GSH. ${ }^{13}$ The expression profiles obtained under conditions of non-photoactivation of the QDs indicated that the cells experienced oxidative stress when treated with Cd-containing QDs, most probably due to intracellular degradation of the nanocrystals with concomitant release of $\mathrm{Cd}^{2+}$ ions ${ }^{14}{ }^{14}$ contrast, incubation with InP/ZnS QDs did not result in any detectable over-expression of genes correlated with oxidative stress at any tested concentration, demonstrating once again the very low in vitro toxicity of these nanocrystals under the investigated conditions (Fig. 4A and B, green bars). All results presented so far revealed a higher resistance of the epithelial cell line A549 compared to the neuronal cell line SH SY5Y towards the treatment with Cdcontaining QDs. In particular, considering the expression profiles presented in Fig. $4 \mathrm{~A}$ and B, it can be observed that the Gpx gene was over-expressed only in A549 cells. Gpx is the most important $\mathrm{H}_{2} \mathrm{O}_{2}$-scavenging enzyme, closely associated with the maintenance of reduced glutathione. It has been reported that A549 cells can efficiently counteract the Cd-induced generation of ROS, likely due to constitutively high levels of glutathione ${ }^{15}$ It has also been shown that these cells are able to develop resistance to cadmium by an enhanced expression of $\gamma$-glutamylcysteine synthetase, the enzyme catalyzing the ratedetermining step in cellular glutathione synthesis. ${ }^{15}$ More recently, it was found that Cd-resistant A549 subclones overexpress the gene encoding for glutathione peroxidase (GPX2), possibly leading to a higher antioxidant defense in these cells. This enzyme plays a fundamental role in the protection of the airway epithelium under oxidative stress conditions. ${ }^{16,17}$

The significantly higher toxicity of Cd-containing QDs shown by the neuronal cell line SH SY5Y is probably a direct consequence of the leach of $\mathrm{Cd}^{2+}$ ions from the QDs. Studies have shown that $\mathrm{Cd}^{2+}$ ions produce severe alteration of calcium homeostasis and an increase of the oxidative stress experienced by the cell, which results in apoptosis of primary neurons as well as PC12 and SH SY5Y cell lines..$^{18}$ In particular, it has been shown that $\mathrm{Cd}^{2+}$ ions induce an increase of intracellular $\mathrm{Ca}^{2+}$ $\left(\left[\mathrm{Ca}^{2+}\right]_{\mathrm{i}}\right)$, which mediates the activation of the MAPK and mTOR pathways, determining neuronal death under stress conditions. We have, therefore, measured the level of $\left[\mathrm{Ca}^{2+}\right]_{\mathrm{i}}$ using the fluorescent dye Fluo-3/AM, ${ }^{18}$ for both cell lines after treatment with $10 \mathrm{nM}$ CdSe/ZnS QDs or InP/ZnS QDs.

The results showed a significant increase in $\left[\mathrm{Ca}^{2+}\right]_{\mathrm{i}}$ only for the treatment with Cd-containing QDs (Fig. 4C and D, red bars), while the InP-based QDs did not produce any appreciable increase (Fig. 4C and D, blue bars). The neuronal cell line gave, as expected, a higher increase of $\left[\mathrm{Ca}^{2+}\right]_{\mathrm{i}}$ compared to the epithelial line (Fig. 4D), confirming the higher sensitivity of these cells. The detrimental increase in $\left[\mathrm{Ca}^{2+}\right]_{\mathrm{i}}$ could be completely suppressed by pretreatment with chelating agents, such as EGTA or BAPTA-AM. Taken together, these results indicate that the observed cellular responses were indeed most likely due to the intracellular release of $\mathrm{Cd}^{2+}$ ions.

TUNEL assays were performed to reveal possible damage to cellular DNA. While the percentage of TUNEL positive nuclei remained below $1 \%$ even for treatments with $5 \mathrm{nM} \mathrm{InP/ZnS} \mathrm{QDs}$ (Fig. 5A and B, blue bars), the same amount of CdSe/ZnS QDs
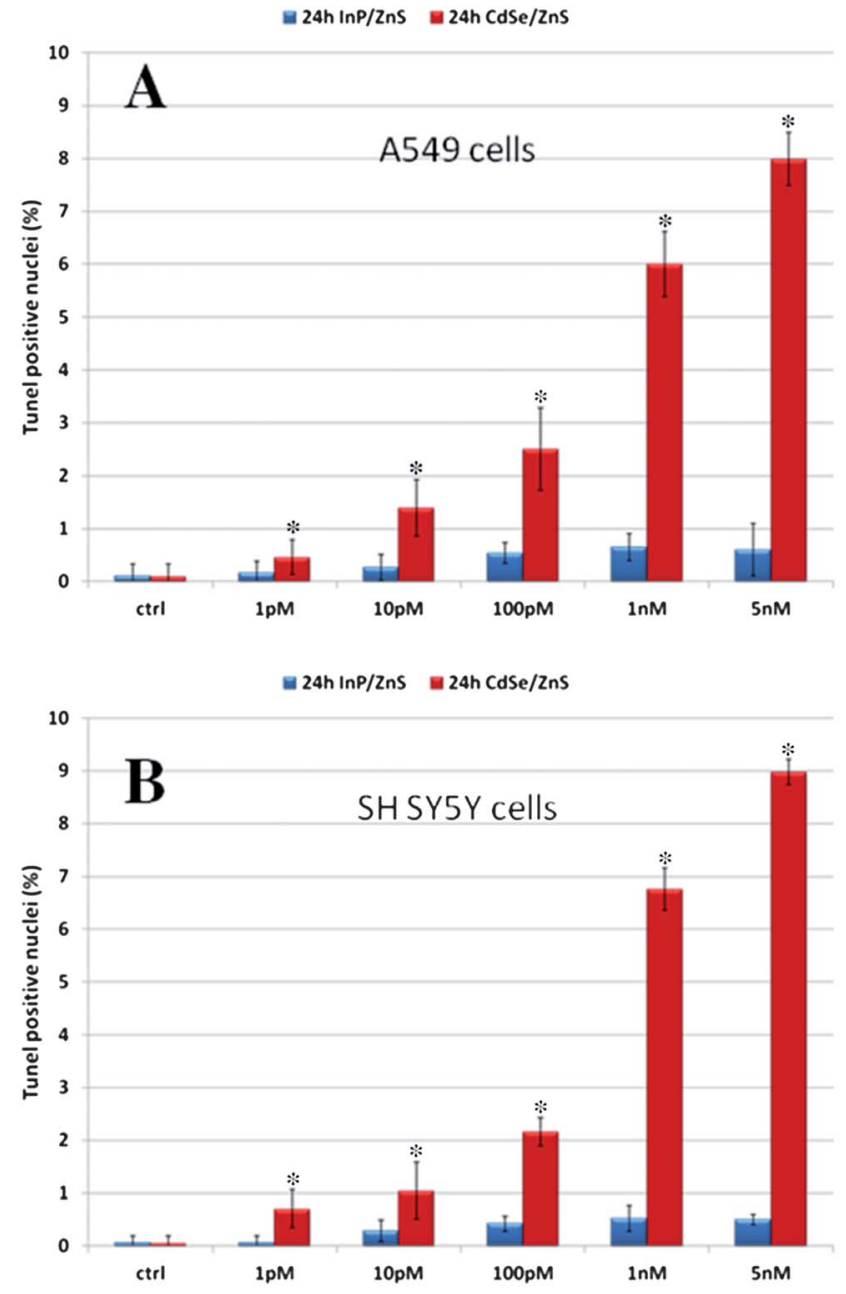

Fig. 5 (A and B) TUNEL assay on A549 and SH SY5Y cells incubated with increasing concentrations of InP/ZnS and CdSe/ZnS QDs. Results are reported after $24 \mathrm{~h}$ incubation; ctrl indicates the negative control (in the absence of QDs). Data are reported as mean \pm SD from three independent experiments; ${ }^{*} P<0.05$ compared with control $(n=8)$.

produced $8 \%$ positive nuclei for A549 cells and $9 \%$ for SH SY5Y cells (Fig. 5A and B, red bars). These data hinted once again at intracellular release of $\mathrm{Cd}^{2+}$ ions, which has been shown to heavily interfere with DNA repair machinery, for instance mediating conformational changes of protein $\mathrm{p} 53 .^{19,20}$

Finally, the intracellular distribution of CdSe/ZnS and InP/ ZnS QDs was investigated by confocal microscopy. Representative images of the two cell lines treated with QDs are shown in Fig. 6. In both cases we found that the nanocrystals were internalized similarly by the cells according to their very similar size and surface chemistry (and protein corona), and localized predominantly in the cytoplasm and in the perinuclear region. We then quantified the cellular uptake by ICP-AES measurements. These quantitative analyses revealed that the amounts of $\mathrm{Cd}$ or In for a given cell line were practically indistinguishable, indicating identical uptake for the two QD types, which was again expected due to their very similar properties in the cell culture medium. In particular, $24 \mathrm{~h}$ incubation with $1 \mathrm{nM}$ QDs gave: $1.80 \pm 0.13 \mathrm{fmol}$ of $\mathrm{Cd}$ and $1.81 \pm 0.10 \mathrm{fmol}$ of In for A549 

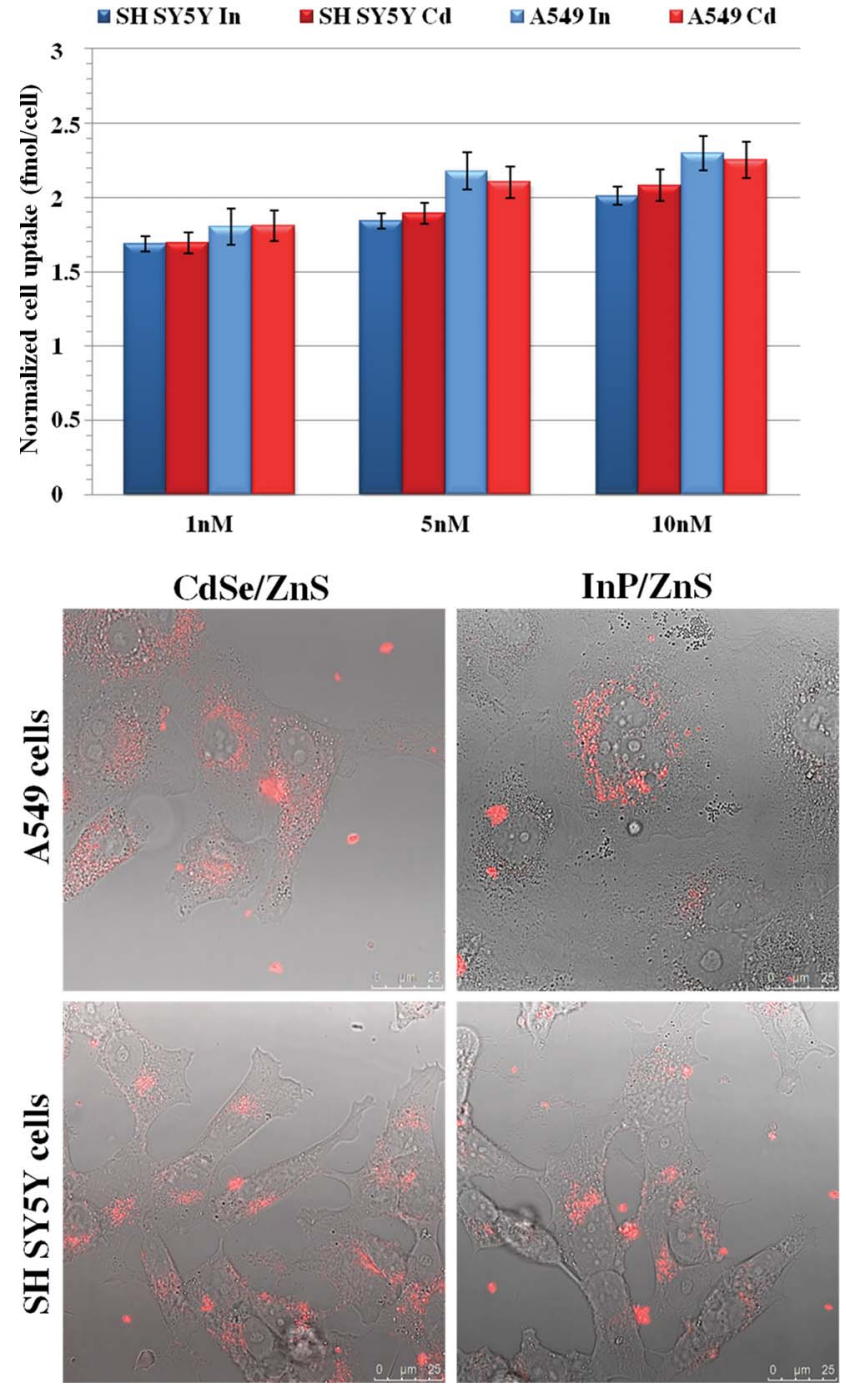

Fig. 6 (Top) Bioaccumulation of QDs in A549 and SH SY5Y cells. Cells were exposed at 1, 5, and $10 \mathrm{nM}$ of CdSe/ZnS and InP/ZnS QDs for $24 \mathrm{~h}$. Data are reported as mean \pm SD from three independent experiments; (bottom) representative confocal-microscopy images of SH SY5Y and A549 cells treated with 5 $\mathrm{nM}$ InP/ZnS or CdSe/ZnS QDs for $24 \mathrm{~h}$. In all images, red spots represent the emission from InP/ZnS or CdSe/ZnS QDs (cells were imaged in bright field).

cells, and $1.69 \pm 0.07 \mathrm{fmol}$ of Cd and $1.69 \pm 0.05 \mathrm{fmol}$ of In for SH SY5Y cells. However, the two investigated cell lines seem to have a different capability of internalizing nanocrystals, with the epithelial cell line A549 internalizing, at all times and concentrations tested, slightly more QDs compared to the $\mathrm{SH}$ SY5Y neurons.

In summary, our in vitro studies showed very clearly that, given a certain QD size and surface chemistry, CdSe/ZnS QDs produced toxic effects on A549 cells as well as on SH SY5Y cells, whereas InP/ZnS QDs were well tolerated at all investigated conditions. Furthermore, our measurements point out that, under conditions of non-photoactivation, the main toxicity cause can be ascribed to the intracellular release of $\mathrm{Cd}^{2+}$ ions, which occurred despite the $\mathrm{ZnS}$ shell, as shown in Fig. 2. On the other hand, the good biocompatibility shown by InP/ZnS QDs was derived from the combined lower release of metal ions from the QD core and the much reduced reactivity of indium.

\section{In vivo toxicity investigations}

Drosophila is an excellent model for toxicological ${ }^{21,22}$ and genetic studies ${ }^{23,24}$ due to its short life cycle, high genetic homology with the human genome, and limited ethical issues. Fruit flies have been recently exploited to study the toxicity of some chemicals ${ }^{22}$ and nanoparticles ${ }^{25-28}$ showing their suitability for in vivo screening of nanomaterials. Here we report the results of our studies on the toxicity of CdSe/ZnS and InP/ZnS QDs in fruit flies fed with QD-supplemented food. We focused on real-time qPCR to clarify the mechanisms underlying QD toxicity, investigating variations in expression levels of genes involved in stress response and DNA damage, such as $h s p 70, h s p 83, p 53$ and Dredd genes.

Flies were fed with food containing two different sub-nanomolar concentrations of CdSe/ZnS or InP/ZnS QDs (100 and 500 $\mathrm{pM}$ ), or alternatively with food supplemented with an equal amount of nanocrystal supernatant solution and with standard food as control. As shown in Fig. 7, hsp70 and hsp 83 were overexpressed in flies treated with CdSe/ZnS QDs ( 3 to 5 times for the $100 \mathrm{pM}$ and up to 10 times for the $500 \mathrm{pM}$ QD-enriched food), indicating a significant and systemic toxicity of CdSe/ZnS QDs. Hsp70 and hsp83 are proteins involved in the stress response, and are part of the heat shock protein (Hsp) family. Up-regulation of Hsps is important to counteract proteotoxic effects since these proteins play various roles, including chaperoning other proteins during synthesis, folding, assembly and degradation. The heat shock response is induced in a protective way in response to systemic toxicity, involving generation of abnormal proteins along with alteration of cellular functions. The expression of Hsps is also strictly related to increased ROS generation. ${ }^{29}$

We also observed an approximately 3-fold over-expression of p53 (for 100 pM QD-enriched food), indicating the presence of

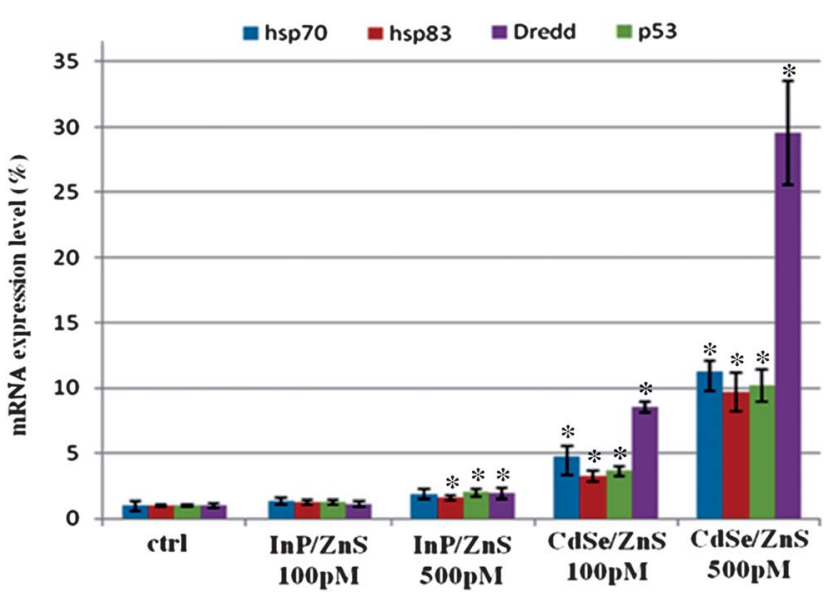

Fig. 7 mRNA expression levels (analyzed by RT-qPCR) for Drosophila flies treated with two different concentrations (100 or $500 \mathrm{pM}$ ) of InP/ZnS or CdSe/ZnS QDs. The table lists the primers used in the RT-qPCR experiments. Data are reported as mean \pm SD from three independent experiments; ${ }^{*} P<0.05$ compared with control $(n=8)$. 
genomic perturbation. p53 is a critical component of cellular mechanisms that responds to genotoxic stresses, such as DNA damage and hypoxia, maintaining genomic integrity by arresting cell-cycle progression and/or by inducing apoptosis. ${ }^{30,31}$
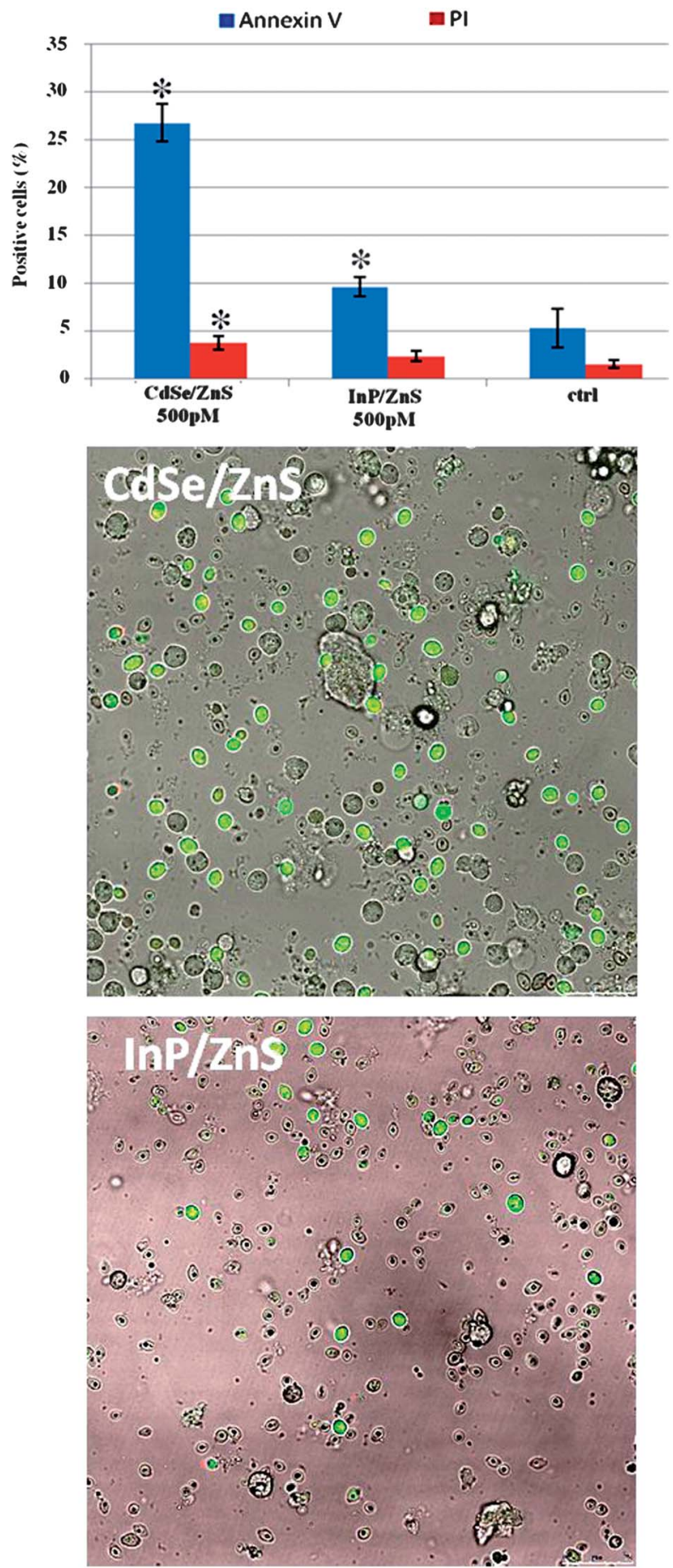

Fig. 8 (Top) Apoptosis/necrosis assay performed on circulating haemocytes. Data are reported as mean \pm SD from three independent experiments; ${ }^{*} P<0.05$ compared with control $(n=8)$. (Bottom) Representative confocal images of Drosophila larval haemocytes treated with CdSe/ZnS or InP/ZnS QDs. Green fluorescence shows annexin V-FITC positive haemocytes.
Finally, the expression levels of Dredd showed that cellular death induced by treatment with CdSe/ZnS QDs in Drosophila was mostly a consequence of apoptosis. The expression of Dredd was approximately 8-fold the control for $100 \mathrm{pM}$, and 25-30 times the control for $500 \mathrm{pM}$ QD-enriched food. In contrast, Drosophila flies treated with InP/ZnS QDs did not present any significant increase in gene expression related to systemic stress (hsp70 and $h s p 83$ ), genome damage repair (p53), or apoptosis (Dredd), compared to the controls.

A direct necrosis/apoptosis test on Drosophila larval hemocytes was also carried out (Fig. 8). These cells are primarily involved in the immune response of the larvae and their physiological function is very similar to that of nucleated blood cells in mammals. A high apoptotic rate is a sign of systemic intoxication involving all insect tissues. Combined annexin $\mathrm{V}$ and propidium iodide (PI) staining showed indeed a high apoptosis rate for flies treated with CdSe/ZnS QDs in comparison to the control or to flies treated with InP/ZnS QDs, in agreement with the gene expression data reported above. Yet, due to the extreme sensitivity of Drosophila larval hemocytes to genotoxic compounds, we observed a slight increase of the apoptotic rate even in the case of flies treated with $\mathrm{InP} / \mathrm{ZnS}$ QDs. This might be ascribed to the local generation of some ROS species due to QD oxidation ${ }^{5}$ along with accumulation of In or $\mathrm{Zn}$ ions.

\section{Conclusions}

Our systematic study on the toxicity of water soluble core/shell $\mathrm{CdSe} / \mathrm{ZnS}$ and InP/ZnS QDs with comparable physical and chemical properties, except the nature of the particle core, very clearly shows that InP/ZnS QDs are a significantly safer alternative to CdSe/ZnS QDs. We show that this conclusion holds for in vitro (cell culture) as well as for in vivo (animal model Drosophila) applications. The CdSe/ZnS QDs were observed to induce: (1) cell membrane damage; (2) conditions of oxidative stress in the cells as indicated by the upregulation of genes coding for antioxidant and detoxifying enzymes; (3) damage of the genetic material and (4) interference with $\mathrm{Ca}^{2+}$ homeostasis. All these effects may be mainly ascribed to the presence of $\mathrm{Cd}^{2+}$ and indeed we could show leaching of ions from the particle core despite the two-layer ZnS shell. Since In(III) ions were also observed to leach in comparable amounts from InP/ZnS QDs, our study indicates that they must have a much lower intrinsic toxicity compared to $\mathrm{Cd}^{2+}$. Furthermore, the high toxicity of CdSe/ZnS QDs compared to InP/ZnS QDs does not depend on higher particle internalization and is clearly observable for cell lines which should be considered "robust" towards $\mathrm{Cd}^{2+}$ poisoning, as well as for more delicate neuronal cell lines. Finally, conditions of systemic and non-specific toxicity and strong induction of cell apoptosis are also evident upon administration of Cd-containing QDs with the diet to the animal model Drosophila, while no such effects were observed for a comparable treatment with InP/ZnS QDs. While the toxicity of Cd-containing QDs has long been recognized, this study shows the importance of having well characterized nanomaterials with comparable physical and chemical 
properties for meaningful comparative toxicity tests in the case of newly developed nanomaterials.

\section{Experimental}

\section{InP/ZnS synthesis}

InP/ZnS QDs were synthesized according to a published procedure. ${ }^{5}$ Briefly, hexadecylamine ( $96 \mathrm{mg}, 0.4 \mathrm{mmol}$ ), stearic acid $(57 \mathrm{mg}, 0.2 \mathrm{mmol})$, zinc undecylenate $(340 \mathrm{mg}, 0.8 \mathrm{mmol})$ and indium chloride ( $44 \mathrm{mg}, 0.2 \mathrm{mmol}$ ) were mixed with $4 \mathrm{~mL}$ octadecene (ODE) under an inert atmosphere $\left(\mathrm{Ar}\right.$ or $\mathrm{N}_{2}$ ) in a flask equipped with a thermometer and a condenser. The reaction mixture was heated to $270{ }^{\circ} \mathrm{C}$ and tris-(trimethylsilyl) phosphine $(0.2 \mathrm{mmol}, 2 \mathrm{~mL}$ of $0.1 \mathrm{M}$ solution in octadecene) was rapidly added. The temperature was decreased and maintained at $240{ }^{\circ} \mathrm{C}$ for $20 \mathrm{~min}$. The solution was then cooled down in a water bath at $20^{\circ} \mathrm{C}$. Zinc diethyldithiocarbamate $(144 \mathrm{mg}$, $0.2 \mathrm{mmol}$ ) was added to the mixture at room temperature and the temperature was increased and kept at $180{ }^{\circ} \mathrm{C}$ for $10 \mathrm{~min}$ and $240{ }^{\circ} \mathrm{C}$ for $20 \mathrm{~min}$. Timing started when the thermometer reached the desired temperature. The reaction mixture was cooled down to room temperature and $8 \mathrm{~mL}$ toluene were added. The mixture was centrifuged at $2500 \mathrm{~g}$ for $5 \mathrm{~min}$ and the precipitate was discarded. The particles were precipitated by adding $42 \mathrm{~mL}$ of ethanol to the orange supernatant solution and recovered by centrifugation $(20 \mathrm{~min}, 2500 \mathrm{~g})$. The $\mathrm{InP} / \mathrm{ZnS}$ pellet was redissolved in $3 \mathrm{~mL}$ of toluene.

QDs were transferred into an aqueous environment by addition of $800 \mu \mathrm{L}$ butanol, $1000 \mu \mathrm{L}$ borate buffer $(\mathrm{pH} \mathrm{9,} 200$ $\mathrm{mM})$ and $8 \mu \mathrm{L}$ mercaptopropionic acid (MPA) $(10 \mu \mathrm{mol})$ to 200 $\mu \mathrm{L}$ of a $5 \mu \mathrm{M}$ QD solution. The mixture was heated at $50^{\circ} \mathrm{C}$ for 15 min. The two phases were separated and the aqueous layer containing the InP/Zn-MPA was purified by four rounds of washing/filtration on a $10 \mathrm{kDa}$ molecular weight cutoff filter (Vivaspin 500) with $50 \mathrm{mM}$ borate buffer at $\mathrm{pH}$ 9. The purified QDs were dissolved in borate buffer at the desired $\mathrm{pH}$ and stored at $4{ }^{\circ} \mathrm{C}$.

\section{CdSe/ZnS synthesis}

CdSe QDs were synthesized following a method adapted from the literature. ${ }^{32}$ Briefly, cadmium oxide (CdO) $(0.026 \mathrm{~g}, 0.20$ $\mathrm{mmol}$ ) and oleic acid (OA, $0.895 \mathrm{~g}, 3.17 \mathrm{mmol})$ were added to 10 $\mathrm{mL}$ ODE. This mixture was degassed for $5 \mathrm{~min}$ and heated under nitrogen to $250{ }^{\circ} \mathrm{C}$ until the mixture became colorless. The selenium precursor (TOPSe) was prepared by mixing Se $(0.01 \mathrm{~g}, 0.127 \mathrm{mmol}$ ) with trioctylphosphine (TOP, $0.415 \mathrm{~g}, 1.12$ $\mathrm{mmol}$ ) and ODE $(2 \mathrm{~mL})$ under $\mathrm{N}_{2}$ into a sealed vial until the solution became light yellow. This solution was rapidly injected into the CdO-ODE mixture at $260{ }^{\circ} \mathrm{C}$. The solution was then cooled down using a water bath directly after the injection of the selenium precursor.

Under a $\mathrm{N}_{2}$ atmosphere, TOP $(0.415 \mathrm{~g}, 1.12 \mathrm{mmol})$, hexamethyldisilathiane ((TMS)2S) $(0.084 \mathrm{~g}, 0.5 \mathrm{mmol})$, and dimethylzinc $(0.3 \mathrm{~mL}, 2.0 \mathrm{M}$ in toluene, $0.5 \mathrm{mmol})$ were diluted to $5 \mathrm{~mL}$ with ODE. $2.5 \mathrm{~mL}$ of this solution were injected into the CdSe QD solution at $170{ }^{\circ} \mathrm{C}$ followed by drop wise addition of the remaining $2.5 \mathrm{~mL}$ over $5 \mathrm{~min}$. The temperature was then allowed to drop and maintained at $100{ }^{\circ} \mathrm{C}$ for $3 \mathrm{~h}$ for QD annealing. QDs were purified by 3 consecutive extractions with $100 \mathrm{~mL} \mathrm{1:1}$ hexane-methanol in a separatory funnel. The unreacted $\mathrm{CdO}$ and oleic acid are soluble in the lower methanol phase which can be discarded while the QDs are only soluble in the hexane-ODE upper phase. A large excess of ethanol was finally added to the hexane phase to precipitate the QDs and the sample was centrifuged at $7000 \mathrm{~g}$ for $1 \mathrm{~min}$. The QD pellet was taken up in an appropriate volume of toluene to reach an optical density of approximately 4 at $400 \mathrm{~nm}$. Aliquots of this QD solution were stored in the dark in air-tight vials.

QDs were transferred into an aqueous environment by ligand exchange. To this end, $1 \mathrm{~mL}$ of concentrated QD solution was diluted to $5 \mathrm{~mL}$ with methanol. MPA $(50 \mu \mathrm{L})$ was added and the mixture was adjusted to $\mathrm{pH} 10$ using tetramethylammonium hydroxide pentahydrate (TMAH). This solution was stirred at room temperature for $12 \mathrm{~h}$. At the end, QDs were separated from excess MPA by precipitation upon addition of excess ethyl acetate followed by centrifugation at $7000 \mathrm{~g}$ for $5 \mathrm{~min}$. The supernatant was discarded and the pellet was dried at room temperature for $1 \mathrm{~h}$. Finally the pellet was redissolved in $2 \mathrm{~mL}$ of doubly distilled water and the solution was filtered through a $0.2 \mu \mathrm{M}$ membrane filter (Millipore, Billerica, MA), and stored at room temperature, protected from light.

\section{In vitro assays}

Cell cultures. Human lung carcinoma cells A549 (Interlab Cell Line Collection IST Genova, Italy, ICLC number HTL03001) and human neuroblastoma cells SH SY5Y (ICLC number HTL95013) were cultured in T25 flasks (Sarstedt) in high glucose DMEM (Sigma Aldrich) supplemented with 10\% (v/v) fetal bovine serum (Sigma Aldrich) and $1 \%(\mathrm{v} / \mathrm{v}) 10000 \mathrm{U} \mathrm{mL}^{-1}$ penicillin and $10000 \mathrm{U} \mathrm{mL}^{-1}$ streptomycin (Sigma Aldrich). The cells were maintained under standard cell culture conditions $\left(5 \% \mathrm{CO}_{2}, 95 \%\right.$ humidity and $37{ }^{\circ} \mathrm{C}$ in a Thermo Scientific incubator) and harvested every 3 days.

WST-8 CYTOTOXICITY ASSAY. The metabolic activity of A549 and SH SY5Y cells was measured after 24 and $48 \mathrm{~h}$ of exposure to $\mathrm{CdSe} / \mathrm{ZnS}$ and InP/ZnS, utilizing colorimetric assays based on the detection of highly water-soluble tetrazolium salt WST-8 (2-(2-methoxy-4-nitrophenyl)-3-(4-nitrophenyl)-5-(2,4-disulfophenyl)-2 $\mathrm{H}$-tetrazolium, monosodium salt) (Cell Counting Kit-8 Fluka); assays were performed in 96-well plates (Sarstedt) for each time ( 24 and $48 \mathrm{~h}$ ). The cells were seeded in microplates at a density of 10000 cells per well and cultured for 24 and $48 \mathrm{~h}$. Different amounts of QDs dispersed in cell culture medium stock solution were added into different wells obtaining final QD concentrations of $1,10,100,500 \mathrm{pM}$ and $1 \mathrm{nM}$. A final concentration of 5\% DMSO in medium was used as the positive control for both cell lines; this treatment generated a reduction in viability to approx. $80-90 \%$ compared to the negative control (data not shown in the graphs). Eight replicates were performed for each investigated point including the controls (ctrl = untreated cells) and blanks (medium only). A $10 \mu \mathrm{L}$ aliquot of WST-8 solution was added to each well. The 96 well microplates 
were incubated for $3 \mathrm{~h}$ in a humidified atmosphere of $5 \% \mathrm{CO}_{2}$ at $37{ }^{\circ} \mathrm{C}$. Subsequently, the orange WST- 8 formazan product was measured at a wavelength of $460 \mathrm{~nm}$ in a Fluo Star Optima (BMG LABTECH) microplate reader. Data were collected by Control Software and elaborated with MARS Data Analysis Software (BMG LABTECH). To express the cytotoxicity, the average absorbance of the wells containing cell culture medium without cells was subtracted from the average absorbance of the solvent control, 5\% DMSO or QD treated cells. The percentage of cell viability was calculated using the following equation: (absorbance $_{\text {treated }} /$ absorbance $\left._{\text {control }}\right) \times 100$.

LDH LEAKAGE ASSAY. A549 and SH SY5Y cells were seeded in a 96-well plate and treated with both types of QDs following the procedures reported for the WST- 8 assay. After 24 and 48 hours of cell-QD interaction, the lactate dehydrogenase (LDH) leakage assay was performed in microplates by applying the CytoToxONE Homogeneous Membrane Integrity Assay reagent (Promega), following the manufacturer's instructions. LDH released in the extracellular environment was measured by a 10 -minute coupled enzymatic assay that results in the conversion of resazurin into fluorescent resorufin $(560 \mathrm{Ex} / 590 \mathrm{Em})$ in a Fluo Star Optima (BMG LABTECH) microplate reader. The same assay was performed onto untreated cells as negative control. Results were normalized with respect to the negative control (expressed as $100 \%)$. The positive control consisted in treatment of the cells with $0.9 \%$ Triton $\mathrm{X}-100$ and gave leakage values in the range of $700-800 \%$ (data not reported). Data were expressed as mean $\pm \mathrm{SD}$.

IN VITRO GENE EXPRESSION LEVEL BY REAL-TIME QPCR. SOD1, SOD2, CAT and Gpx mRNA expression levels were examined by real time quantitative Reverse Transcription PCR following treatment of A549 and SH SY5Y cells with $5 \mathrm{nM}$ QDs for $24 \mathrm{~h}$. Positive controls were obtained by treatment with a free radical generator $\left(\mathrm{H}_{2} \mathrm{O}_{2}\right.$, assay concentration $\left.100 \mu \mathrm{M}\right)$ for $30 \mathrm{~min}$. Total RNA was isolated from cells using an Aurum Total RNA mini Kit (Biorad) following the manufacturer's instructions; the amount of RNA in each sample was determined by a Nanodrop, and RNA quality was analyzed by agarose gel electrophoresis (1.2\%). First-strand cDNA was prepared from $3 \mu \mathrm{g}$ of total RNA using Enhanced Avian Reverse Transcriptase (Sigma Aldrich) and oligo(dT)18 primers in $20 \mu \mathrm{L}$ reaction volume, and $2.5 \mu \mathrm{g}$ were digested with RNase (Sigma Aldrich). Real-time quantitative PCR was performed with an ABI 7500 thermal cycler (Applied Biosystem) following the manufacturer's suggestions and using SYBR Green-based detection of PCR products. Melting curves were examined after amplification to exclude the presence of unspecific amplification targets. For each gene we used $10 \mathrm{ng}$ of cDNA mixed with $10 \mu \mathrm{L}$ of $10 \times$ Express SYBR Green qPCR SuperMix premixed with ROX (Invitrogen), $2 \mu \mathrm{L}$ of $4 \mu \mathrm{M}$ gene specific primer mix and $7 \mu \mathrm{L}$ of DEPC-treated water. Reaction conditions for all genes were: initial denaturation at $95{ }^{\circ} \mathrm{C}$ for 10 min followed by 45 cycles of $15 \mathrm{~s}$ at $95{ }^{\circ} \mathrm{C}, 1 \mathrm{~min}$ at $60^{\circ} \mathrm{C}$. This program was followed by a melting curve program $\left(60-95{ }^{\circ} \mathrm{C}\right.$ with a heating rate of $0.1{ }^{\circ} \mathrm{C} \mathrm{s}^{-1}$ and continuous fluorescence measurements). Relative expression was calculated by Applied Biosystem Software through the $\Delta \Delta$ Ct method, using RN18S1 ribosomal RNA expression as an internal control for each sample. The primers used in Real-Time qPCR analysis were designed by on-line Primer-BLAST software of NCBI (the list is reported below): endogenous control gene RN18S1 primers (forward: TCTAGATAACCTCGGGCCGA and reverse: ACGGC GACTACCATCGAAAG); CAT primers (forward: TGTTGCTGGA GAATCGGGTTC and reverse: TCCCAGTTACCATCTTCTGTGTA); SOD1 primers (forward: AGGGCATCATCAATTTCGAG and reverse: TGCCTCTCTTCATCCTTTGG); SOD 2 primers (forward: AAACGTGACTTTGGTTCCTT and reverse: CCCGTTCCTTATT GAAACCA); Gpx primers (forward: TTCCCGTGCAACCAGTTTG and reverse: TTCACCTCGCACTTCTCGAA).

$\left[\mathrm{CA}_{2}{ }^{+}\right]_{\mathrm{I}}$ DETECTION. Levels of $\left[\mathrm{Ca}_{2}{ }^{+}\right]_{\mathrm{i}}$ for A549 and SH SY5Y cells were measured after 24 exposure to $\mathrm{CdSe} / \mathrm{ZnS}$ or InP/ZnS QDs. The cells were seeded in complete growth medium in a 96-well plate following the procedures reported for the WST-8 assay. The following day, the cells were treated with $5 \mathrm{nM}$ QDs for $24 \mathrm{~h}$ following pre-incubation with or without BAPTA/AM $(30 \mathrm{mM})$ and EGTA (100 mM) for 30 min with 8 replicates of each treatment. After incubation, the cells were washed 2 times with PBS and subsequently were loaded with $5 \mathrm{mM}$ Fluo-3/AM for $30 \mathrm{~min}$ at $37{ }^{\circ} \mathrm{C}$ in the dark and washed once with PBS to remove the extracellular Fluo-3/AM. Finally, fluorescent intensity was recorded in a Fluo Star Optima (BMG LABTECH) microplate reader (485 $\mathrm{nm}$ excitation and $520 \mathrm{~nm}$ emission). $\left[\mathrm{Ca}_{2}{ }^{+}\right]_{\mathrm{i}}$ variation of single treatment was expressed as a percentage increase of fluorescence intensity relative to the controls \pm SD. The reproducibility of the results was confirmed by performing four independent biological replicates.

TUNEL ASSAY. A549 and SH SY5Y cells, exposed to QDs for 24 $\mathrm{h}$, were fixed and stained by using Click-iT TUNEL imaging assay (molecular probes) according to the manufacturer's instructions. With this technique it is possible to highlight DNA nicks; detection is based on a click reaction between EdUTP and an azide modified AlexaFluor 647. To provide a positive control, DNase I was used to generate strand breaks in the DNA (100\% TUNEL positive nuclei). The cells were finally counterstained with Hoechst 33342. The samples were imaged by confocal microscopy. TUNEL positive nuclei were stained both with Alexa647 and Hoechst 33342, TUNEL negative nuclei only with Hoechst 33342.

CONFOCAL MICROSCOPY. Uptake of QDs in cells was tracked by confocal microscopy. Both cell lines were incubated with CdSe/ $\mathrm{ZnS}$ and InP/ZnS QDs at a final concentration of $100 \mathrm{pM}$ for $24 \mathrm{~h}$ at $37^{\circ} \mathrm{C}$ in $5 \% \mathrm{CO}_{2}$. The following day, cell culture medium was removed from the cells and replaced by standard complete medium. After $24 \mathrm{~h}$ of incubation, the samples were washed with PBS pH 7.4 (Sigma), harvested, and then fixed in buffered $3.7 \%$ formaldehyde (Sigma) for $20 \mathrm{~min}$. After washing, the samples were imaged by confocal microscopy (Leica TCS SP5 AOBS).

ICP ANALYSES. The amount of internalized Cd and In per cell was quantified by inductively coupled plasma atomic emission spectroscopy (ICP-AES, Agilent 720/730 spectrometer). A549 and SH SY5Y cells were seeded in a 6 well plate (Sarsted) at density $10^{6}$ cells per mL. The cells were treated for 24 and $48 \mathrm{~h}$ with 100 pM QDs. The untreated cells were used as control. Five replicates were analyzed for each treatment. After incubation, the 
cells were detached by trypsinization and washed twice by centrifugation in sterile PBS. The number of cells was determined by a TC10 automatic cell counter (Biorad) and cell suspensions were standardized at $10^{6}$ cells per $\mathrm{mL}$. The samples were dissolved overnight in $1 \mathrm{~mL}$ of concentrated $\mathrm{HCl}-\mathrm{HNO}_{3}$ $3: 1(\mathrm{v} / \mathrm{v})$, diluted to $10 \mathrm{~mL}$ with ultrapure water, and the resulting solution was directly analyzed by ICP-AES.

\section{In vivo assays}

DROSOPHILA MELANOGASTER STRAIN AND CULTURE CONDITIONS. The flies and larvae of wild-type Drosophila melanogaster (Oregon $\mathrm{R}+$ ) were cultured at $24 \pm 1{ }^{\circ} \mathrm{C}$ on standard Drosophila food, containing agar, corn meal, sugar, yeast and nepagin (methyl- $p$ hydroxybenzoate).

QD TREATMENT. For toxicity assays, CdSe/ZnS and InP/ZnS QDs were formulated in the diet. Two different QD final concentrations (100 and $500 \mathrm{pM}$ ) were dispersed in the food and used for experiments. In particular, the solution containing QDs was added to the food before solidification, thoroughly mixed and finally poured into vials. TEM analyses showed that the QDs do not significantly aggregate after mixing with the Drosophila food, maintaining a good degree of monodispersity.

DROSOPHILA MELANOGASTER GENE EXPRESSION LEVEL BY REALTIME QPCR. Third instar larva extracts were prepared by homogenizing larvae in groups of 10 in cold solution of RNA later (Sigma). Hsp70, Hsp83, p53 and Dredd mRNA expression levels were examined by performing real time quantitative Reverse Transcription PCR in larvae fed with food containing $100 \mathrm{pM}$ and $500 \mathrm{pM}$ of QDs and larvae fed with normal food. Total RNA was isolated from flies using TRI Reagent ${ }^{\circledR}$ (Sigma). The amount of RNA in each sample was determined by Nanodrop, and RNA quality was analyzed via agarose gel electrophoresis $(1.2 \%)$. Real time PCR was performed using directly RNAs in one-step reaction in an ABI 7500 thermocycler (Applied Biosystems). For each gene we used $1 \mu \mathrm{L}$ of $0.5 \mu \mathrm{g} \mu \mathrm{L}^{-1}$ of RNA solution mixed with $10 \mu \mathrm{L}$ of $10 \times$ Express Syber Green qPCR SuperMix premixed with ROX (Invitrogen), $2 \mu \mathrm{L}$ of $4 \mu \mathrm{M}$ gene specific primers mix, $0.5 \mu \mathrm{L}$ of Express SuperScript Mix for oneStep Syber GreenER (Invitrogen) and $6.5 \mu \mathrm{L}$ of DEPC-treated water. Reaction conditions for all genes were: $50{ }^{\circ} \mathrm{C}$ for 5 minutes to perform cDNA synthesis, immediately followed by the PCR quantification program, repeated 40 times $(15 \mathrm{~s}$ at $95{ }^{\circ} \mathrm{C}, 1 \mathrm{~min}$ at $60{ }^{\circ} \mathrm{C}$ ). This program was followed by a melting curve program $\left(60-99^{\circ} \mathrm{C}\right.$ with a heating rate of $0.1^{\circ} \mathrm{C} \mathrm{s}^{-1}$ and continuous fluorescence measurements). Relative expression was calculated from cycle threshold values ( $\Delta \Delta \mathrm{Ct}$ method) using the RpL32 (ribosomal protein L32) expression as an internal control for each sample. The primers used in real time qPCR analysis were designed by on-line Primer-BLAST software of NCBI. In particular, the endogenous control gene Rpl32 primer (forward: CGA GTT GAA CTG CCT TCA AGA TGA CCA and reverse: CCG ACT GGT GGC GGA TGA AGT G); hsp70 primer (forward: AGG GTC AGA TCC ACG ACA TC and reverse: CGT CTG GGT TGA TGG ATA GG); hsp83 primer (forward: TGG AGG CTC TGC AGG CTG GT and reverse: GGC GAC CAG GTA GGC GGA GT) specific for the target sequence NM_079175.2; p53 primer (forward: TGC GGA CAC AAA TCG CAA CTG CT and reverse: ACG ACG CGG ACT TGT GAA GAC TC); Dredd primer (forward: AGC ACC CCG ATC TTT CGC TAT TGC and reverse: ACA TCC GAT AGC CGT GGC CTG A. All target sequences are reported as NCBI accession number.

StATISTICAL ANALYSES. GraphPad Prism 5 statistical analysis software was used for all statistical analyses performed in this work (GraphPad Prism version 5.00 for Windows, GraphPad Software, San Diego, California, USA). In particular, for experiments with Drosophila, the survival distributions (lifespan curves) were assessed in terms of significance using the nonparametric log-rank (Mantel-Cox) test, while real time qPCR results were analyzed by two-way ANOVA, and all gene expressions were compared to the controls by the Bonferroni post-test. In all the other in vitro and in vivo assays, data were analyzed by one-way ANOVA and compared to the corresponding control by the Bonferroni post-test. Differences between treated samples and controls were considered statistically significant for $P$-values $<0.05\left(^{*}\right)$ and non-significant for $P$-values $>0.05$.

\section{Acknowledgements}

The authors gratefully acknowledge V. Fiorelli and B. Antonazzo for the expert technical assistance.

\section{References}

1 W. A. Hild, M. Breunig and A. Goepferich, Eur. J. Pharm. Biopharm., 2008, 68, 153-168.

2 S. J. Soenen, P. Rivera-Gil, J.-M. Montenegro, W. J. Parak, S. C. De Smedt and K. Braeckmans, Nano Today, 2011, 6, 446-465.

3 T. Pellegrino, L. Manna, S. Kudera, T. Liedl, D. Koktysh, A. L. Rogach, S. Keller, J. Rädler, G. Natile and W. J. Parak, Nano Lett., 2004, 4, 703-707.

4 J. Gao, K. Chen, R. Luong, D. M. Bouley, H. Mao, T. Qiao, S. S. Gambhir and Z. Cheng, Nano Lett., 2011, 12, 281-286.

5 H. Chibli, L. Carlini, S. Park, N. M. Dimitrijevic and J. L. Nadeau, Nanoscale, 2011, 3, 2552-2559.

6 S. J. Clarke, C. A. Hollmann, F. A. Aldaye and J. L. Nadeau, Bioconjugate Chem., 2008, 19, 562-568.

7 S. Xu, J. Ziegler and T. Nann, J. Mater. Chem., 2008, 18, 26532656.

8 G. Maiorano, S. Sabella, B. Sorce, V. Brunetti, M. A. Malvindi, R. Cingolani and P. P. Pompa, ACS Nano, 2010, 4, 7481-7491.

9 B. Sahoo, M. Goswami, S. Nag and S. Maiti, Chem. Phys. Lett., 2007, 445, 217-220.

10 M. A. Malvindi, V. Brunetti, G. Vecchio, A. Galeone, R. Cingolani and P. P. Pompa, Nanoscale, 2012, 4, 486-495.

11 D. J. Bharali, D. W. Lucey, H. Jayakumar, H. E. Pudavar and P. N. Prasad, J. Am. Chem. Soc., 2005, 127, 11364-11371.

12 D. R. Cooper, N. M. Dimitrijevic and J. L. Nadeau, Nanoscale, 2010, 2, 114-121.

13 R. L. T. Matsumoto, D. H. M. Bastos, S. Mendonça, V. S. Nunes, W. Bartchewsky, M. L. Ribeiro and P. de Oliveira Carvalho, J. Agric. Food Chem., 2009, 57, 1775-1780. 
14 K. G. Li, J. T. Chen, S. S. Bai, X. Wen, S. Y. Song, Q. Yu, J. Li and Y. Q. Wang, Toxicol. in Vitro, 2009, 23, 1007-1013.

15 E. L. Hatcher, Y. Chen and Y. J. Kang, Free Radical Biol. Med., 1995, 19, 805-812.

16 A. Singh, T. Rangasamy, R. K. Thimmulappa, H. Lee, W. O. Osburn, R. Brigelius-Flohé, T. W. Kensler, M. Yamamoto and S. Biswal, Am. J. Respir. Cell Mol. Biol., 2006, 35, 639-650.

17 F. Croute, B. Beau, J.-C. Murat, C. Vincent, H. Komatsu, F. Obata and J.-P. Soleilhavoup, J. Toxicol. Environ. Health, Part A, 2005, 68, 703-718.

18 B. Xu, S. Chen, Y. Luo, Z. Chen, L. Liu, H. Zhou, W. Chen, T. Shen, X. Han, L. Chen and S. Huang, PLoS One, 2011, 6, e19052.

19 T. Schwerdtle, F. Ebert, C. Thuy, C. Richter, L. H. F. Mullenders and A. Hartwig, Chem. Res. Toxicol., 2010, 23, 432-442.

20 W. K. B. Khalil, E. Girgis, A. N. Emam, M. B. Mohamed and K. V. Rao, Chem. Res. Toxicol., 2011, 24, 640-650.

21 B. H. Jennings, Mater. Today, 2011, 14, 190-195.

22 D. Bhargav, M. Pratap Singh, R. C. Murthy, N. Mathur, D. Misra, D. K. Saxena and D. K. Chowdhuri, Ecotoxicol. Environ. Saf., 2008, 69, 233-245.
23 J. Botas, Nat. Genet., 2007, 39, 589-591.

24 G. J. Lieschke and P. D. Currie, Nat. Rev. Genet., 2007, 8, 353367.

25 M. Ahamed, R. Posgai, T. J. Gorey, M. Nielsen, S. M. Hussain and J. J. Rowe, Toxicol. Appl. Pharmacol., 2010, 242, 263269.

26 X. Liu, D. Vinson, D. Abt, R. H. Hurt and D. M. Rand, Environ. Sci. Technol., 2009, 43, 6357-6363.

27 P. P. Pompa, G. Vecchio, A. Galeone, V. Brunetti, G. Maiorano, S. Sabella and R. Cingolani, Nanoscale, 2011, 3, 2889-2897.

28 P. P. Pompa, G. Vecchio, A. Galeone, V. Brunetti, S. Sabella, G. Maiorano, A. Falqui, G. Bertoni and R. Cingolani, Nano Res., 2011, 4, 405-413.

29 M. P. Singh, M. M. K. Reddy, N. Mathur, D. K. Saxena and D. K. Chowdhuri, Toxicol. Appl. Pharmacol., 2009, 235, 226243.

30 M. Zylicz, F. W. King and A. Wawrzynow, EMBO J., 2001, 20, 4634-4638.

31 K. Somasundaram, Front. Biosci., 2000, 5, D424-D437.

32 A. Subashini, M. K. Karl, A. Ammar, R. C. Alessandra, M. Zuze, L. C. Vicki, V. M. Nikos and S. W. Michael, Nanotechnology, 2005, 16, 2000. 